\title{
STUDY OF SEED DORMANCY ORIGINS IN THREE ATLAS PISTACHIO ECOTYPES (PISTACIA ATLANTICA DESF.)
}

\author{
Labdelli, A. ${ }^{1,2}$ - AdDA, A. ${ }^{1}$ - Bouchenafa, N. ${ }^{1}$ - Rebiai, A. ${ }^{3}-$ Zebib, B. ${ }^{4}-$ MeraH, O. ${ }^{5,6^{*}}$ \\ ${ }^{1}$ Laboratory of Agro-Biotechnology and Nutrition in Semi-Arides Zones, Ibn Khaldoun \\ University of Tiaret, Tiaret, Algeria
}

${ }^{2}$ Scientific and Technical Research Centre for Arid Areas (CRSTRA), BP 1682 RP, Biskra, Algeria

${ }^{3}$ University of El Oued, VTRS Laboratory, P. O. Box 789, El-Oued, Algeria

${ }^{4}$ Agronutition SAS Laboratories, Parc Activestre, 3 allée de l'Orchidée, F-31390 Carbonne, France

${ }^{5}$ Laboratoire de Chimie Agro-industrielle, LCA, Université de Toulouse, INRA, Toulouse, France

${ }^{6}$ Département Génie Biologique, IUT A, Université Paul Sabatier, Auch, France

\author{
*Corresponding author \\ e-mail: othmane.merah@ensiacet.fr
}

(Received $4^{\text {th }}$ Apr 2019; accepted $2^{\text {nd }}$ Sep 2019)

\begin{abstract}
The Atlas pistachio (Pistacia atlantica Desf.), a rustic tree distributed in different bioclimatic areas, is rapidly declining, particularly in Algeria. Among the actions to be undertaken is the launch of a restocking program. Nevertheless, Atlas pistachio seed dormancy is an obstacle limiting its germination and obtaining seedlings. The aims of the present study are to define the nature of seed germination inhibitors and to propose pretreatments that would limit their effects. Seeds were collected from three locations in Algeria. Quantitative and qualitative traits of phenolic compounds and total antioxidant activity were determined at three levels, namely, seed, epicarp and kernel. Germination was investigated in seeds with epicarp, epicarp removed, and with or without $\mathrm{H}_{2} \mathrm{O}_{2}$ treatment. Results showed that whole seed germination is not effective. Scarification by removing epicarp did not improve the germination rate. Chemical analyses indicated that seeds, kernel and epicarp were rich in total phenolic compounds. These compounds are known to limit seed germination in several species. Application of hydrogen peroxide induced a significant increase in seed germination rate in the three ecotypes. $\mathrm{H}_{2} \mathrm{O}_{2}$ caused inhibition of polyphenol compounds effects on germination. The results indicated that the inhibitory effect of phenolic compounds can be found at the kernel level instead of the epicarp. However, studied genotypes indicated that only one ecotype was distinguished by seed dormancy that originated in the epicarp and kernel.
\end{abstract}

Keywords: pistachio, seeds, germination, inhibition, polyphenols

\section{Introduction}

Wild pistachio (Pistacia atlantica Desf.) is a rustic and xerophytic tree, adapted to dry climates. In Algeria, it even inhabits pre-Saharan areas where it plays important roles on the ecological and socio-economic levels. It is a tree species of the genus Pistacia L. which is endangered in Algeria. This species has been declining from year to year in response to anthropogenic factors and, in addition, due to the problems related to its regeneration. Similarly, plants that beyond the emergence stage by escaping pastures are confronted with arid climate problems that cause even more damage (Ait Said et al., 2011). Atlas pistachio produces oilseeds rich in polyunsaturated fatty acids, 
mainly oleic and linoleic acid (Yousfi et al., 2002; Farhoosh et al., 2009; Yazdanpanah and Baghereyanmanesh, 2015) and exhibit orthodox storage characteristics (Joley, 1960; Ayfer and Serr, 1961).

Seed germination is one of the most important stages of the plant life cycle. Germination in the narrow sense is an exceptionally complex process that begins with water uptake and is associated with many metabolic, cellular, and molecular events, which enable the radicle to emerge from the seed (Barba-Espín et al., 2012). The efficient progression of germination determines the nature of seedling formation and the proper development of mature plants. However, Pistacia atlantica seeds present a dormancy phenomenon which greatly limits their germination.

Seed dormancy is separated into two types, the first imposed by the epicarp and the second by the embryo (Joley, 1960; Bewley and Black, 1994). The endocarp can reduce the imbibition rate (Crane and Forde, 1974). Embryonic dormancy is related to the environmental conditions which occur at the time of harvest and when maturation of seeds takes place (Vallèe et al., 1999). Seeds of this tree are encompassed by a hard epicarp, which makes germination difficult (Isfendiyaroglu and Özeker, 2001; Abu-Qaoud, 2007).

Phenolic compounds are the products of secondary metabolism in plants, providing essential functions in their reproduction and growth, acting as defense mechanisms against pathogens, parasites, and predators, as well as contributing to the color of plants (Liu, 2007). The inhibitory effects of phenolic compound on seed germination are closely related to the regulation of endogenous auxins, epicarp permeability and oxygen supply to the embryo (Bewley and Black, 1994). Polyphenols and flavonoids produced in the fruit or seed can inhibit germination (Baskin and Baskin, 1998). The reactivation of metabolism following seed imbibition may supply an important source of reactive oxygen species (ROS) (Bailly, 2004). Hydrogen peroxide $\left(\mathrm{H}_{2} \mathrm{O}_{2}\right)$ is a reactive molecule that plays a dual role in plant physiological and developmental processes, and in resistance to stress. The accumulation of $\mathrm{H}_{2} \mathrm{O}_{2}$ and of other ROS has been identified in seed physiology during imbibition and during early stages of germination (Schopfer, 2001; Bailly, 2004).

Preservation of the Atlas pistachio requires protection of the existing population, as well as planting of new trees. Realization of this last operation is based on the mastery seed germination and seedling production. Nevertheless under different conditions, the germination of pistachio seeds, though slow, requires the removal of factors which reduce its rate.

The poor germination of Atlas pistachio seeds seriously limits its regeneration. Different treatments have been used to increase the germination rate, without characterizing the factors that are responsible for seed dormancy. Abu Qaoud (2007) showed that germination rate was improved by seed scarification, which explains that seed dormancy is due to the mechanical resistance of the epicarp.

This study attempts to define the biochemical factors imposing the seed dormancy and their variation through the genetic variability thus the limitation of their effects by pretreatments application.

\section{Materials and methods}

\section{Plant materials}

Seeds of Pistacia atlantica accessions were collected from 10 trees in each of three locations in Algeria from the beginning of October to November 2015 (Table 1; Figs. 1 and 2). 
Table 1. Geographical data of Algerian studied zones where seeds sampling are collected

\begin{tabular}{c|c|c|c|c}
\hline Designation & Bioclimatic stage & Altitude (m) & Latitude (N) & Longitude (E) \\
\hline Djelfa & Arid & 630 & $34^{\circ} 02^{\prime} 11^{\prime \prime}$ & $03^{\circ} 40^{\prime} 22^{\prime \prime}$ \\
Bechar & Hyper-arid & 979 & $32^{\circ} 04^{\prime} 6^{\prime \prime}$ & $02^{\circ} 18^{\prime} 5^{\prime \prime} \mathrm{W}$ \\
Batna & Semi-arid & 1027 & $35^{\circ} 37^{\prime} 10^{\prime \prime}$ & $6^{\circ} 22^{\prime} 13^{\prime \prime}$ \\
\hline
\end{tabular}

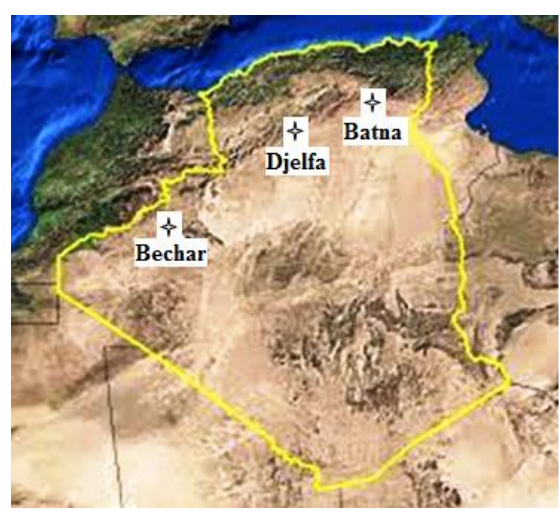

Figure 1. Repartition map of the different sites of Pistacia atlantica ecotypes
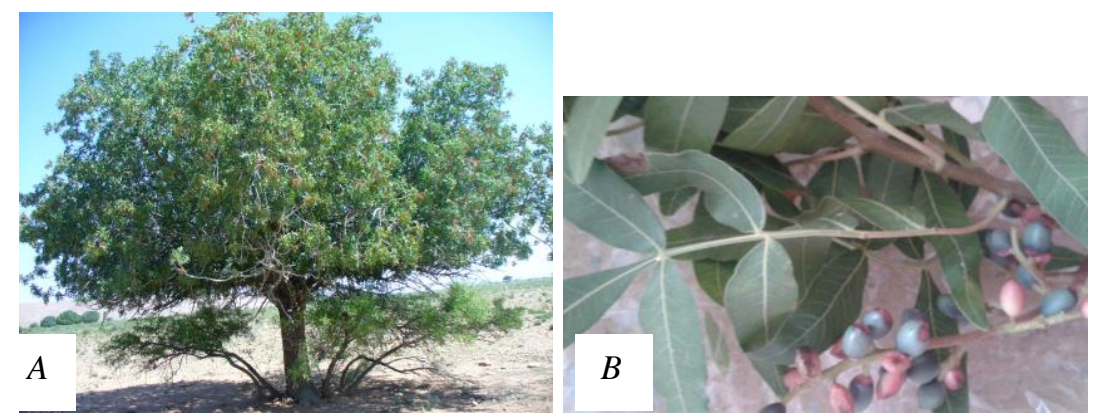

Figure 2. Atlas Pistachio tree (A) and twigs with fruits (B)

\section{Biochemical analysis}

Plant sampling and preparation of extracts

One gram of each sample of seed, kernel and epicarp were crushed into powder using a mortar grinder (RM 200-Retsch) mixed with $20 \mathrm{ml}$ of methanol and stirred for $48 \mathrm{~h}$ in the dark at room temperature. The mixture was filtered through a GHP filter with $0.45 \mu \mathrm{m}$ pores. The solvent was then removed under reduced pressure in a rotary evaporator at $60^{\circ} \mathrm{C}$. The residue (crude extract) was dissolved in $3 \mathrm{ml}$ of methanol for analysis.

\section{Determination of total phenolic compounds}

The total polyphenol content (TPC) was quantified using the Folin-Ciocalteau phenol reagent, according to the protocol of Singleton et al. (1999). The method is based on the colored reaction of phenolic compounds with the reagent. Folin-Ciocalteau reagent is reduced to a blue colored oxide at $\mathrm{pH} 9.0$ upon reaction with phenols. In a typical 
experiment, $200 \mu \mathrm{l}$ of the final methanolic solution was mixed with $1 \mathrm{ml}$ of FolinCiocalteu reagent (10\%) and $0.8 \mathrm{ml}$ of $\mathrm{Na}_{2} \mathrm{CO}_{3}(7.5 \%)$. After incubation for $30 \mathrm{~min}$ at room temperature in dark, the absorbance was determined at $765 \mathrm{~nm}$ using a UV-1800 spectrophotometer (Shimadzu UV-VIS). Results were expressed as $\mathrm{mg}$ of gallic acid equivalent per $\mathrm{g}$ of fresh weight (mg GAE/g FW). For each sample three replicates were analyzed. The choice of methanol as solvent was based on the results of Belyagoubi et al. (2016), who showed that crude methanolic extracts were more effective than petroleum ether, chloroform, acetone and water extracts for determining total phenolic content and antioxidant activity of $P$. atlantica seeds.

\section{Evaluation of total antioxidant activity (TAA)}

The total antioxidant activity (TAA) of methanolic extract samples was estimated using the phosphomolybdenum method of Prieto et al. (1999), based on the reduction of Mo (VI) to Mo (V) by the extractedion and subsequent formation of a specific green phosphate/Mo $(\mathrm{V})$ complex at acidic $\mathrm{pH}$. Aliquots $(1 \mathrm{ml})$ of reagent solution $(0.6 \mathrm{M}$ sulfuric acid, $28 \mathrm{mM}$ sodium phosphate and $4 \mathrm{mM}$ ammonium molybdate) were added to $100 \mu \mathrm{L}$ of each sample (three replicates) and incubated at $95{ }^{\circ} \mathrm{C}$ for $90 \mathrm{~min}$. The mixture was then cooled at room temperature. The absorbance of all samples was measured at $695 \mathrm{~nm}$. Total antioxidant activity was expressed as $\mathrm{mg}$ gallic acid equivalent per $\mathrm{g}$ of fresh weight (mg GAE/g FW).

\section{Qualitative analysis of phenolic compounds}

The chromatographic system for the separation, analysis of phenolic acids and flavonoids were carried out with Shimadzu model prominence liquid chromatography, thermostatic column compartment, online degasser and an UV-visible detector model SPD-20A (operating at $268 \mathrm{~nm}$ ). An analytical column used was a Shim-pack VP-ODS C18 (4.6 mm $\times 250 \mathrm{~mm}, 5 \mu \mathrm{m})$, (Shimadzu Co., Japan). A binary gradient linear system consisting of acetonitrile (A) and $0.2 \%$ acetic acid in water (B) was used. Gradient method was generated by starting with $90 \% \mathrm{~B}$; then decreasing to $86 \% \mathrm{~B}$ in $6 \mathrm{~min}$, to $83 \% \mathrm{~B}$ in $16 \mathrm{~min}$, to $81 \% \mathrm{~B}$ in $23 \mathrm{~min}$, to $77 \% \mathrm{~B}$ in $28 \mathrm{~min}$, held at $77 \% \mathrm{~B}$ in $28-35 \mathrm{~min}$, to $60 \% \mathrm{~B}$ in $38 \mathrm{~min}$, to $90 \% \mathrm{~B}$ in $50 \mathrm{~min}$; at a flow rate of $1 \mathrm{~mL} / \mathrm{min}$. Quantification of separated peaks was performed by calibration with standard gallic acid (GA), chlorogenic acid (CGA), vanillic acid (VA), caffeic acid (CA), p-coumaric acid (p-CA), vanillin $(\mathrm{V})$, rutin $(\mathrm{RU})$, naringin (NAR), and quercetin $(\mathrm{QE})$. The volume injected is $20 \mu 1$. The phenolic compositions were quantified by plotting a standard curve with the respective standards (Fig. 1).

\section{Seed germination rate}

Seeds of Pistacia atlantica (Fig. 2) were divided into two groups, with and without epicarp (achieved by mechanical scarification). They were imbibed in distilled water (control) or $4 \% \mathrm{H}_{2} \mathrm{O}_{2}$ as pretreatment for $48 \mathrm{~h}$. A total of 216 seeds were used for each ecotype (with and without epicarp) and were placed in Petri dishes (9 cm diameter) with filter paper moistened with distilled water. The experimental design was completely randomized with three replications per treatment. Seeds were incubated at $25{ }^{\circ} \mathrm{C}$ in the dark. The rate germination $(\mathrm{G} \%)$ was calculated according to the following equation: $\mathrm{G} \%=(\mathrm{NGG} / \mathrm{NTG}) \times 100$, where NGG was the number of germinated seeds and NTG was the total number of tested seeds. 


\section{Statistical analysis}

All data were subjected to a one- and two-way analysis of variance (ANOVA) using the STATISTICA software package (StatSoft, Tulsa, USA). Mean comparison was performed by Duncan test at $5 \%$ probability level.

\section{Results}

\section{Polyphenols and antioxidant activity}

The results (Table 2) showed that there was a significant ecotype effect on the TPC content at the seed, epicarp and kernel level. Regarding the TAA, there was a significant effect only in relation to seed content.

Our results indicated that the phenolic compound content of the epicarp was significantly higher than seed or kernel, irrespective of the geographic origins (Table 2). The highest TPC content of the epicarp was observed in seeds from Djelfa and the lowest in seeds fromn Bechar. In the kernel, the total phenolic content increased by $20 \%$ from values in Bechar seeds to those from Djelfa (Table 2). The TAA at the seed level depended significantly on the nature of the ecotypes studied. However, seed origin had only a small influence on this activity in epicarp and kernel (Table 2). Total antioxidant activity was extremely different in seeds from different locations and values varied by nearly two-fold between ecotypes from Bechar and those from Batna (Table 2). The total antioxidant activity was highest at the epicarp level and the lowest values at the kernel level (Table 2). Indeed, TAA in the epicarp was nearly 1.7 and 4.5 times that in the whole seed and kernel, respectively (Table 2). Moreover, the higher the TPC value, the higher the antioxidant activity, irrespective of seed origin or the specific seed part investigated.

Table 2. Means values of total phenolic contents (TPC) and total antioxidant activity (TAA) founded in seed, kernel and epicarp of Pistacia atlantica harvested from three geographic zones in Algeria

\begin{tabular}{c|c|c|c|c|c|c}
\hline \multirow{2}{*}{ Ecotype } & \multicolumn{3}{|c|}{ TPC (mg GAE/g FW) } & \multicolumn{3}{c}{ TAA (mg GAE/g FW) } \\
\cline { 2 - 7 } & Seed & Kernel & Epicarp & Seed & Kernel & Epicarp \\
\hline Djelfa & $257.7 \pm 2.7^{\mathrm{a}}$ & $93.6 \pm 5.8^{\mathrm{a}}$ & $450.4 \pm 17.9^{\mathrm{a}}$ & $71.8 \pm 14.2^{\mathrm{a}}$ & $42.34 \pm 1.57^{\mathrm{a}}$ & $115.5 \pm 3.8^{\mathrm{a}}$ \\
Bechar & $237.8 \pm 2.4^{\mathrm{b}}$ & $77.7 \pm 0.2^{\mathrm{b}}$ & $367.4 \pm 32.5^{\mathrm{b}}$ & $82.0 \pm 6.9^{\mathrm{a}}$ & $44.84 \pm 8.55^{\mathrm{a}}$ & $87.2 \pm 20.1^{\mathrm{a}}$ \\
Batna & $192.7 \pm 3.6^{\mathrm{c}}$ & $81.7 \pm 6.1^{\mathrm{b}}$ & $324.8 \pm 1.8^{\mathrm{b}}$ & $49.4 \pm 10.1^{\mathrm{b}}$ & $36.37 \pm 5.60^{\mathrm{a}}$ & $126.7 \pm 30.3^{\mathrm{a}}$ \\
Mean & 229.4 & $84.3^{* * *}$ & 380.9 & 67.74 & 41.18 & 109.8 \\
F values & $57.1^{* * *}$ & $8.76^{*}$ & $26.6^{* *}$ & $7.1^{*}$ & $1.6^{\mathrm{ns}}$ & $2.8^{\mathrm{ns}}$ \\
\hline
\end{tabular}

$*, * *, * * *$ : Significant at $\mathrm{P} \leq 0.05 ; \mathrm{P} \leq 0.01 ; \mathrm{P} \leq 0.001$, respectively. $\mathrm{ns}$ : not significant. $\mathrm{F}$ values Means indicated by different letters are significantly different using the Duncan test at 0.05 probability and the significance of ecotype Factor it also displayed

\section{Phenolic identification by HPLC}

The phenolic compounds including gallic acid, chlorogenic Acid, vanillic acid, caffeic acid, Vanillin, p-coumaric acid, rutin, naringin and quercetin were identified and quantified in epicarp, kernel and seed (Table $3 a, b)$. 
The phenolic acid contents, which consist mainly of gallic and chlorogenic acids, are variable according to the ecotypes, at the three measurement sites (Table $3 a, b$ ). The highest phenolic acids content was recorded at the epicarp of Djelfa (D) seeds with $94.15 \mathrm{mg} / \mathrm{gFW}$ and the lowest value was measured at the Batna seeds epicarp (B) with $0.206 \mathrm{mg} / \mathrm{gFW}$.

The results indicated that the quercetin is the major flavonoids constituent, identified in epicarp as well as in seed and kernel extracts. The total flavonoids highest levels were found in the epicarp of Djelfa and Batna seeds with respective values of $459.86 \mathrm{mg} / \mathrm{gFW}$ and $104.48 \mathrm{mg} / \mathrm{gFW}$. The lowest levels of total flavonoids were found in the three ecotypes kernels, where the lowest grade has reached $2.26 \mathrm{mg} / \mathrm{gFW}$ (Bechar).

Finally, the results show that the different constituents of the Atlas pistachio seeds are poor in tannins. The condensed tannins are present at a low level, only in the epicarp of Djelfa and Batna ecotypes.

Table 3a. Quantitative and qualitative analysis by HPLC of phenolic acids ( $\mathrm{mg} / \mathrm{g} \mathrm{FW}$ ) of seed, kernel and epicarp in different ecotypes

\begin{tabular}{c|c|c|c|c|c|c|c}
\hline & Ecotypes & $\begin{array}{c}\text { Gallic } \\
\text { acid }\end{array}$ & $\begin{array}{c}\text { Chlorogenic } \\
\text { acid }\end{array}$ & $\begin{array}{c}\text { Vanilic } \\
\text { acid }\end{array}$ & $\begin{array}{c}\text { Caffeic } \\
\text { acid }\end{array}$ & $\begin{array}{c}\text { p-Coumaric } \\
\text { acid }\end{array}$ & $\begin{array}{c}\text { Total phenolic } \\
\text { acids }\end{array}$ \\
\hline \multirow{3}{*}{ Seed } & Djelfa & 6.277 & 9.83 & 0.094 & ND & 0.156 & 16.357 \\
& Bechar & 6.437 & 9.705 & 0.073 & 0.034 & 0.146 & 16.246 \\
& Batna & 1.462 & 3.482 & ND & 0.012 & 0.031 & 4.988 \\
\hline \multirow{4}{*}{ Kernel } & Djelfa & 1.649 & 1.515 & 0.059 & 0.080 & ND & 3.303 \\
& Bechar & 1.700 & 3.833 & 0.018 & ND & ND & 5.550 \\
& Batna & 0.468 & 1.497 & ND & ND & ND & 1.965 \\
\hline \multirow{3}{*}{ Epicarp } & Djelfa & 48.8 & 43.858 & 0.824 & 0.39 & 0.279 & 94.15 \\
& Bechar & 1.622 & 0.917 & ND & ND & ND & 2.54 \\
& Batna & 0.041 & 0.126 & 0.019 & 0.021 & ND & 0.206 \\
\hline
\end{tabular}

ND: not determined

Table 3b. Quantitative and qualitative analysis by HPLC of flavonoids and tanins $(\mathrm{mg} / \mathrm{g}$ $F W)$ of seed, kernel and epicarp in different ecotypes

\begin{tabular}{c|c|c|c|c|c|c}
\hline \multicolumn{5}{c}{ Flavonoids } & Tannins \\
\hline \multirow{3}{*}{ Seed } & Ecotypes & Rutin & Naringin & Quercetin & $\begin{array}{c}\text { Total } \\
\text { flavonoids }\end{array}$ & Vanillin \\
\hline \multirow{3}{*}{ Kernel } & Djelfa & 1.025 & 0.07 & 43.985 & 45.08 & 0.111 \\
& Bechar & 1.133 & 0.297 & 41.798 & 43.228 & ND \\
& Batna & 0.128 & 0.211 & 42.845 & 43.183 & ND \\
\hline \multirow{3}{*}{ Epicarp } & Djelfa & 0.144 & ND & 2.937 & 3.081 & ND \\
& Bechar & 0.133 & ND & 2.126 & 2.259 & ND \\
& Batna & 0.258 & ND & 7.154 & 7.413 & ND \\
\hline & Djelfa & 5.459 & 1.51 & 452.894 & 459.863 & 0.07 \\
& Bechar & 0.21 & ND & 23.391 & 23.602 & ND \\
& Batna & 0.254 & 0.091 & 104.134 & 104.479 & 0.091 \\
\hline
\end{tabular}

ND: not determined 


\section{Seed germination rate}

Seed germination was tested with or without an epicarp. The results showed that in both situations, seed germination was significantly influenced by ecotype origin, $\mathrm{H}_{2} \mathrm{O}_{2}$ treatment and their interaction (Table 4). No germination was observed, whatever the geographical origin, for whole seeds or for seeds without an epicarp. Pretreatment with $\mathrm{H}_{2} \mathrm{O}_{2}$ significantly increased the germination rate in all of the ecotypes studied (Table 4). However, the interaction between $\mathrm{H}_{2} \mathrm{O}_{2}$ treatment and seed origin had a significant effect on seed germination rate (Table 3). This relationship mirrored distinct reactions based on the seed origin with respect to the $\mathrm{H}_{2} \mathrm{O}_{2}$ pretreatment. In fact, $\mathrm{H}_{2} \mathrm{O}_{2}$ treatment induced germination of seeds with or without an epicarp. Nevertheless, results of pretreatment with $\mathrm{H}_{2} \mathrm{O}_{2}$ were different depending on the presence of an epicarp or not (Table 5). Indeed germination rate of seeds without an epicarp with $\mathrm{H}_{2} \mathrm{O}_{2}$ application was $50 \%$ was higher than in whole seeds similarly treated with $\mathrm{H}_{2} \mathrm{O}_{2}$. Moreover, the ecotypes reacted differently to $\mathrm{H}_{2} \mathrm{O}_{2}$ pretreatment. The Batna ecotype had a 50\% germination rate, while the lowest germination rate was observed in the Djelfa ecotype (Table 5). This difference in germination rate between Djelfa and Batna ecotype was reported for whole seeds and for seeds without an epicarp.

Table 4. F-Test values and the significance of ecotype, $\mathrm{H}_{2} \mathrm{O}_{2}$ treatment and their interaction effects on seed germination on four ecotypes of Pistacia atlantica, with and without epicarp

\begin{tabular}{c|c|c|c}
\hline & Ecotype & $\mathbf{H}_{2} \mathbf{O}_{2}$ Treatment & Ecotype*Treatment \\
\hline Seeds (with epicarp) & $3.58^{\mathrm{ns}}$ & $45.74^{* * *}$ & $3.5^{\mathrm{ns}}$ \\
Seeds (without epicarp) & $22.39^{* * *}$ & $143.97^{* * *}$ & $22.3^{* * *}$ \\
\hline
\end{tabular}

${ }^{* * * *}$ Significant at $\mathrm{P} \leq 0.001 ; \mathrm{ns}$ : not significant

Table 5. Germination rate of seeds with or without epicarp, treated or not with $\mathrm{H}_{2} \mathrm{O}_{2}$ from three ecotypes of Pistacia atlantica

\begin{tabular}{c|c|c|c}
\hline \multirow{2}{*}{ Ecotype } & \multirow{2}{*}{ Treatment } & \multicolumn{2}{|c}{ Germination rate (\%) } \\
\cline { 2 - 4 } & & With epicarp & Without epicarp \\
\hline Djelfa & Control & 0.00 & 0.00 \\
Djelfa & $\mathrm{H}_{2} \mathrm{O}_{2}$ & $11.11 \pm 11$ & $14.7 \pm 2.94$ \\
Bechar & $\mathrm{Control}$ & 0.00 & 0.00 \\
Bechar & $\mathrm{H}_{2} \mathrm{O}_{2}$ & $19.44 \pm 8.3$ & $25 \pm 13.8$ \\
Batna & $\mathrm{Control}_{\text {Batna }}$ & 0.00 & 0.00 \\
\hline
\end{tabular}

\section{Discussion}

Our results showed that removal of the epicarp did not improve seed germination whatever the ecotype (Table 4). This discrepancy may be a result of several environmental and genetic factors. Moreover, our results suggest that seed dormancy is chemical in nature and concerned, not only with the epicarp, but also the kernel (Tables 4 and 5). Among the chemical components that are involved in seed dormancy, phenols and their antioxidant activities are often cited (Panngom et al., 2018). Several methods have been used to overcome seed dormancy and to improve the seed 
germination rate. Among these methods, the use of chemicals has been reported to be more effective (Wada et al., 2011; Barba-Espin et al., 2012; Panuccio et al., 2014; Panngom et al., 2018). In our study, we demonstrated that pretreatment with $\mathrm{H}_{2} \mathrm{O}_{2}$ greatly increased seed germination rates (Table 5). Similar findings have been reported using chemical components to break seed dormancy and increase seed germination in several species, including pea, coriander, carrot, zinnia and quinoa (Wada et al., 2011; Barba-Espin et al., 2012; Panuccio et al., 2014; Szopińska, 2014; Panngom et al., 2018). Many studies report that the progression of seed germination by hydrogen peroxide treatment may be the result of the oxidation of germination inhibitors present in the epicarp and pericarp (Duval and NeSmith, 2000; Ogawa and Iwabuchi, 2001; Conner, 2008; Klein et al., 2008; Huarte and Garcia, 2009; Panngom et al., 2018). The positive effect of $\mathrm{H}_{2} \mathrm{O}_{2}$ on seed germination has been explained by production of $\mathrm{O}_{2}$ resulting by scavenging of $\mathrm{H}_{2} \mathrm{O}_{2}$ for the mitochondrial respiration and metabolic activities (Katzman et al., 2001). Chen et al. (1993) reported that $\mathrm{H}_{2} \mathrm{O}_{2}$ is useful in cracking hard seeds, allowing them to interact with water. The results obtained here showed that the origin of seed dormancy is related to both the kernel and the epicarp. Indeed, total phenol content and their antioxidant activities were higher in both compartments of the seed (Table 2). However, this result was dependent on the origin of the seeds used. Seeds from Batna locality showed similar inhibitory effects in the epicarp and kernel. Moreover, even though total phenol content was four times higher in the epicarp than in the kernel, antioxidant activity of the epicarp was only 2.5 times higher than the kernel. These results could be explained by the presence of chemical components other than phenols acting as antioxidants.

Total polyphenol compounds are mainly involved in the inhibition of seed germination in this plant species which limits water or oxygen absorption or both. Phenolic compounds and alkaloids that can be found in the epicarp and pericarp may inhibit seed germination (Tao and Buta, 1986; Gross and Parthier, 1994; Bhattacharyya et al., 1999). Isfendiyaroglu and Özeker (2001) reported that flavonoids and phenylpropanes played important roles in seed dormancy. Under natural conditions, the presence of total polyphenol compounds in seeds is effective in plant resistance to environmental conditions (Khoyerdi et al., 2016). The pretreatment with $\mathrm{H}_{2} \mathrm{O}_{2}$ that induced the germination (Tables 3 and 4) demonstrated that dormancy in Atlas pistachio seeds has a chemical basis. Among the functions of $\mathrm{H}_{2} \mathrm{O}_{2}$ is the oxidation of total phenolic compounds, contributing to the decomposition of the germination inhibitors (Ogawa and Iwabuchi, 2001). Klein et al. (2008) reported that faster germination of eastern gamagrass seeds exposed to $\mathrm{H}_{2} \mathrm{O}_{2}$ may result from breaking down the inhibitors present in the pericarp, although there may also be a direct physical scarifying effect of this compound. Some studies have reported that $\mathrm{H}_{2} \mathrm{O}_{2}$ is involved abscisic acid catabolism and gibberellin synthesis that, in turn, activates germination (Barba-Espin et al., 2012 and Panngom et al., 2018). The results also showed that the antioxidant activity increases with the increase of the polyphenol content of seeds. The antioxidant activity of phenolic compounds is mainly due to their redox properties, which allow them to act as reducing agents, hydrogen donors and singlet oxygen quenchers. Therefore reduces the endogenous concentration of ROS would improve seed germination (Sangmin et al., 2010).

The results of the present study showed that Atlas pistachio seeds (Pistacia atlantica Desf.) were characterized by a dormancy that inhibits their germination under optimal conditions. Seed scarification (removal of the epicarp) did not modify the germination 
rate whatever the ecotype. Biochemical analysis showed seeds were rich in total phenolic compounds that were probably at the origin of their dormancy. This hypothesis was partly confirmed by the increase in germination rate after treatment of seeds with hydrogen peroxide. In fact, the total phenolic compounds were not only present in the epicarp but also the kernel, which may explain the absence of germination after scarification. Moreover, the distribution (content) of phenols between the kernel and the epicarp was different depending on ecotype studied. It seems that for ecotypes from Djelfa and Bechar, inhibition of germination was essentially localized at the level of the kernel, whereas for the ecotype from Batna this inhibition involved both the epicarp and the kernel. Further investigations are needed to confirm these results and to study the effect of different durations of pretreatment with $\mathrm{H}_{2} \mathrm{O}_{2}$ or other chemicals.

\section{Conclusion}

The low germination rates of Atlas pistachio seeds are due to their dormancy. This dormancy is of chemical nature and is localized at the level of the pericarp and kernel. It is explained by their high content of phenolic compounds that limit their metabolic reactivation during the emergence of latent life during their germination. In fact, there had been an absence of germination of whole or scarified seeds. Germination improved significantly after pretreatment with hydrogen peroxide $\left(\mathrm{H}_{2} \mathrm{O}_{2}\right)$. The application of $\mathrm{H}_{2} \mathrm{O}_{2}$, which is one of the ROS, would inhibit the effects of phenolic compounds, accelerate the dormancy emergence and consequently improve the germination rate of Pistacia atlantica.

\section{REFERENCES}

[1] Abu-Qaoud, H. (2007): Effect of scarification, gibberellic acid and stratification on seed germination of three Pistacia species. - An Najah Univ J. Res (N. Sc.) 2(1): 1-11.

[2] Ait Said, S., Fernandez, C., Greff, S., Derridj, A., Gauquelin, T., Mevy, J. P. (2011): Inter-population variability of leaf morpho-anatomical and terpenoid patterns of Pistacia atlantica Desf. ssp. atlantica growing along an aridity gradient in Algeria. - Flora 206: 397-405.

[3] Ayfer, M., Serr, E. F. (1961): Effects of gibberellin and other factors on seed germination and early growth in Pistacia species. - Proceedings of the American Society for Horticultural Science 77: 308-315.

[4] Bailly, C. (2004): Active oxygen species and antioxidants in seed biology. - Seed Science Research 14: 93-107.

[5] Barba-Espín, G., Hernández, J. A., Diaz-Vivancos, P. (2012): Role of $\mathrm{H}_{2} \mathrm{O}_{2}$ in pea seed germination. - Plant Signaling \& Behavior 7(2): 193-195.

[6] Baskin, C. C., Baskin, J. M. (1998): Seeds. - Academic Press San Diego, CA.

[7] Belyagoubi, L., Belyagoubi-Benhammou, N., Atik-Bekkara, F., Coustard, J. M. (2016): Effects of extraction solvents on phenolic content and antioxidant properties of Pistacia atlantica Desf. fruits from Algeria. - International Food Research Journal 23: 948-953.

[8] Bewley, J. D., Black, M. (1994): Seeds. Physiology of Development and Germination. Plenum Press, New York.

[9] Bhattacharyya, S., Das. B., Ghose, T. K., Bhattacharya, S. (1999): Investigation on seed germination of Nyctanthesarbour-tristis (Oleraceae) in relation to the phenol content. Seed Science and Technology 27: 321-327.

[10] Chen, Z., Silva, H., Klessing, D. F. (1993): Active oxygen species in the induction of plant systemic acquired resistance by salicylic acid. - Science 262: 1883-1886. 
[11] Crane, J. C., Forde, H. I. (1974): Improved Pistacia seed germination. - California Agriculture 28: 8-9.

[12] Conner, P. J. (2008): Effects of stratification, germination temperature and pre-treatment with gibberellic acid and hydrogen peroxide on germination of 'Fry' muscadine (Vitis rotundifolia) seed. - Hort. Sci. 43: 853-856.

[13] Duval, J. R., Ne Smith, D. S. (2000): Treatment with hydrogen peroxide and seed coat removal or clipping improve germination of 'Genesis' triploid watermelon. HortiScience 35: 85-86.

[14] Farhoosh, R., Haddad Khodaparast, M. H., Sharif, A. (2009): Bene hull oil as a highly stable and antioxidative vegetable oil. - European Journal of Lipid Science and Technology 111: 1259-65.

[15] Gross, D., Parthier, B. (1994): Novel natural substances acting in plant growth regulation. - Journal of Plant Growth Regulation 13: 93-114. http://dx.doi.org/10.1007/ BF00210953.

[16] Huarte, R., Garcia, M. D. (2009): Tripsacum dactyloides (L.) L. (Poaceae) caryopsis dormancy and germination responses to scarification, hydrogen peroxide and phytohromes. - Seed Sci. Technol. 37: 544-553.

[17] Isfendiyaroglu, M., Özeker, E. (2001): The relation between phenolic compounds and seed dormancy in Pistacia spp. - Options Méditerranéennes 56: 227-232.

[18] Joley, L. E. (1960): Experiences with propagation of the genus Pistacia. - Proceedings of the Plant Propagators' Society 10: 287-292.

[19] Katzman, L. S., Taylor, A. G., Langhans, R. W. (2001): Seed enhancements to improve spinach germination. - HortiScience 36: 979-981.

[20] Khoyerdi. F. F., Shamshiri, M. H., Estaji, A. (2016): Changes in some physiological and osmotic parameters of several pistachio genotypes under drought stress. - Scientia Horticulturae 198: 44-51. http://dx.doi.org/10.1016/j.scienta.2015.11.028.

[21] Klein, J. D., Wood, L. A., Geneve, R. L. (2008): Hydrogen peroxide and color sorting improves germination and vigor of eastern gamagrass (Tripsacum dactyloides) seeds. Acta Horticulturae 782: 93-97.

[22] Liu, R. H. (2007): Whole grain phytochemicals and health. - Journal of Cereal Science 46: 207-219.

[23] Ogawa, K., Iwabuchi, M. (2001): A mechanism for promoting the germination of Zinnia elegans seeds by hydrogen peroxide. - Plant Cell Physiology 42: 286-291.

[24] Panngom, K., Chuesaard, T., Tamchan, N., Jiwchan, T., Srikongsritong, K., Park, G. (2018): Comparative assessment for the effects of reactive species on seed germination, growth and metabolisms of vegetables. - Scientia Horticulturae 227: 85-91.

[25] Panuccio, M. R., Jacobsen, S. E., Akhtar, S. S., Muscolo, A. (2014): Effect of saline water on seed germination and early seedling growth of the halophyte quinoa. - AoB Plants 6(plu047): 1-18.

[26] Prieto, P., Pineda, M., Aguilar, M. (1999): Spectrophotometric quantitation of antioxidant capacity through the formation of a phosphomolybdenum complex: Specific application to the determination of vitamin E. - Analytical Biochemistry 269: 337-341.

[27] Sangmin, L., Sang-Gyu, K., Chung-Mo, P. (2010): Salicylic acid promotes seed germination under high salinity by modulating antioxidant activity in Arabidopsis. - New Phytologist 188: 626-637.

[28] Schopfer, P. (2001): Hydroxyl radical-induced cell-wall loosening in vitro and in vivo: implications for the control of elongation growth. - The Plant Journal 28: 679-678.

[29] Singleton, V. L., Orthofer, R., Lamuela-Raventos, R. M. (1999): Analysis of total phenols and other oxidation substrates and antioxidants by means of Folin-Ciocalteu reagent. Methods in Enzymology 299: 152-178.

[30] Szopińska, D. (2014): Effects of hydrogen peroxide treatment on the germination, vigour and health of Zinnia elegans seeds. - Folia Hort. 26(1): 19-29. 
[31] Tao, K. L. J., Buta, J. G. (1986): Differential effects of camptothecin and interaction with plant hormones on seed germination and seedling growth. - Plant and Growth Regulation 4: 219-226.

[32] Vallèe, C., Bilodeau, G., De Lanaudière, C. J. (1999): Les techniques de culture en multicellules. - Quebecois Institute of the Decorative Development of Horticulture, Saint-Nicolas, Québec, Canada.

[33] Wada, S., Kennedy, J. A., Reed, B. M. (2011): Seed-coat anatomy and proanthocyanidins contribute to the dormancy of Rubus seed. - Scientia Horticulturae 130: 762-768.

[34] Yazdanpanah, E., Baghereyanmanesh, R. (2015): Quantitative analysis of the seed oil from Pistacia atlantica var. mutica in boyer ahmad. - Indian Journal of Fundamental and Applied Life Sciences 5(4): 84-87.

[35] Yousfi, M., Nedjmi, B., Bellal, R., Ben Bertal, D., Pallad, G. (2002): Fatty acids and sterols of Pistacia atlantica fruit oil. - Journal of the American Oil Chemists' Society 79: 1049-1050. 